\title{
O Conselho Tutelar e as políticas públicas para crianças e adolescentes
}

\author{
HeMerson LUIZ PASE ${ }^{1}$ \\ GABRIELE PADILHA CUNHA ${ }^{2}$ \\ MÁRCIA LEITE BORGES ${ }^{1}$ \\ ANA PAUla DUPUY PATELLA ${ }^{3}$ \\ ${ }^{1}$ Universidade Federal do RIO GRANDE (FURG) / FACULdADE DE DIREITO, RIO GRANDE - RS, BRASIL \\ 2 Universidade federal de Pelotas (UfPel) / Instituto de Filosofia, Sociologia e Política, Pelotas - RS, Brasil

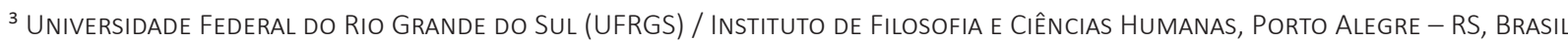

\begin{abstract}
Resumo
O sistema de proteção à criança e ao adolescente foi normatizado no Brasil com a promulgação da Constituição Federal, a criação do Estatuto da Criança e do Adolescente (ECA), bem como do Conselho Tutelar. Neste trabalho, analisa-se o papel do Conselho Tutelar na consolidação da proteção e da fiscalização dos direitos de crianças e adolescentes no município de Pelotas. As hipóteses parcialmente comprovadas afirmam que o Conselho Tutelar tem o protagonismo protetivo e educativo quando da ausência ou omissão dos pais ou familiares. Todavia o isolamento e fragmentação do sistema de proteção, além da postura reativa dos conselheiros e a falta de infraestrutura no trabalho dificultam a efetividade da política. A estratégia metodológica baseou-se na análise qualitativa, e as informações primárias foram obtidas com o auxílio da técnica da entrevista em profundidade.
\end{abstract}

Palavras-chave: Políticas Públicas. Infância e Juventude. Conselho Tutelar.

\section{The Guardianship Council and public policy for children and adolescents}

\begin{abstract}
The protection system for children and adolescents was standardized in Brazil based on the Federal Constitution, the Child and Adolescent Statute, and the Guardianship Council. This article aims to analyze the role of the Guardianship Council in consolidating the protection and enforcement of the rights of children and adolescents in the municipality of Pelotas. Partially proven hypotheses state that the Guardianship Council has the protective and educational role in the absence of parents or family members. However, the isolation and fragmentation of the protection system, as well as the reactive posture of counselors and the lack of infrastructure at work make it difficult for the policy to be effective. Qualitative analysis and the primary information was obtained through in-depth interviews.
\end{abstract}

Keywords: Public policy. Childhood and youth. Guardianship Council.

\section{El Consejo Tutelar y políticas públicas para niños y adolescentes}

\section{Resumen}

El sistema de protección para niños y adolescentes fue estandarizado en Brasil con base en la Constitución Federal, el Estatuto del Niño y del Adolescente y el Consejo Tutelar. Este documento tiene como objetivo analizar el papel del Consejo Tutelar en la consolidación de la protección y la observancia de los derechos de los niños y adolescentes en el municipio de Pelotas. Las hipótesis parcialmente probadas indican que el Consejo Tutelar tiene el papel protector y educativo en ausencia u omisión de los padres o familiares. Sin embargo, el aislamiento y la fragmentación del sistema de protección, así como la postura reactiva de los consejeros y la falta de infraestructura en el trabajo dificultan la efectividad de la política. La estrategia metodológica se basó en el análisis cualitativo y la información primaria se obtuvo a través de la técnica de entrevista en profundidad.

Palabras clave: Políticas públicas. Infancia y juventud. Consejo Tutelar. 


\section{INTRODUÇÃO}

Após o período em que o Brasil viveu sob o autoritarismo da ditatura militar, quando da emergência da redemocratização, houve uma grande esperança de que ocorreria, juntamente com a volta da democracia e instituições democráticas, a consolidação de uma cidadania para todos os brasileiros. Essa expectativa também se desenvolveu com relação aos direitos de crianças e adolescentes brasileiros, tendo em vista que a Constituição Federal promulgada em 1988 (CF/88) passou a garantir, de forma integral, a proteção e a efetivação destes direitos, elevando esta parcela da sociedade à condição de cidadão.

Até o advento desta legislação, crianças e adolescentes eram tratados apenas como extensão de seus pais, a quem pertenciam e, por muitas vezes, como mão de obra gratuita. $O$ contexto era de total abandono social pelo Estado. As crianças e adolescentes eram expostas a violações pelos mais variados setores da sociedade, até mesmo por sua própria família.

Em 13 de julho de 1990, foi aprovado, no Congresso Nacional, o Estatuto da Criança e do adolescente (ECA), resultado das reivindicações advindas de organizações não governamentais de defesa dos direitos da infância e juventude, e de pressões de organizações externas como Organização das Nações Unidas (ONU) na Convenção sobre os Direitos da Criança (1989).

Com a aprovação do ECA, os municípios tornaram-se atores centrais na implementação de políticas públicas de assistência e proteção à criança e ao adolescente. Em razão disso, os criaram os Conselhos Tutelares, órgão responsável pela fiscalização e articulação dentro de uma rede de políticas públicas visando à proteção dos direitos da infância e juventude.

O presente trabalho tem o objetivo de compreender as peculiaridades e as tarefas desempenhadas pelos conselheiros tutelares. Para tanto, partiu-se do seguinte questionamento: qual o papel do Conselho Tutelar na consolidação da proteção e da fiscalização dos direitos de crianças e adolescentes no município de Pelotas?

A hipótese apresentada é a de que o Conselho Tutelar carrega uma potencialidade central no sistema de proteção da criança e do adolescente, pois assume o protagonismo protetivo e educativo quando da ausência ou omissão dos pais ou familiares. Todavia não consegue atingir seu objetivo em razão do isolamento e da fragmentação do sistema de proteção e, também, da postura reativa dos conselheiros e da falta de infraestrutura no trabalho.

A metodologia qualitativa foi escolhida para o teste da hipótese. Iniciou-se, assim, uma pesquisa bibliográfica, bem como uma análise da legislação pertinente, com o intuito de construir um arcabouço teórico consistente, que possibilitasse identificar a contribuição do Conselho Tutelar na proteção de crianças e adolescentes no país. Além disso, buscando confrontar as atribuições legais do Conselho Tutelar com o cotidiano vivido pelos conselheiros no município de Pelotas/RS, foram realizadas entrevistas em profundidade com 12 (doze) conselheiros tutelares em dezembro de 2016 e janeiro e fevereiro de 2017, a fim de averiguar as peculiaridades de implementação das ações sob sua alçada.

\section{Políticas Públicas para a Infância e Juventude}

Até o advento da $\mathrm{CF} / 88$ e do $\mathrm{ECA}$, crianças e adolescentes eram tratados pelo Estado como extensão de seus pais (COSTA, 1993a). Segundo González (2015, p. 26):

[...] dos anos 20 ao final dos anos 80 a legislação brasileira aplicável às crianças e adolescentes (ou menores, conforme a denominação da época) foi regida pelo binômio abandonado/infrator. Destacam-se dois códigos de menores - de 1927 e de 1979 respectivamente, além de inúmeras leis esparsas, das quais pode ser destacada a que criou a Política Nacional do Bem Estar do Menor - PNBEM, em 1964, na esteira da qual foram criadas nos anos 70 as FEBEMs ${ }^{1}$.

O Estado brasileiro, ao longo de sua história, referia-se a estes como "menores". Não zelava por seus direitos mais essenciais, tais como o direito a uma vida digna, em um ambiente familiar saudável que contribuísse para o seu desenvolvimento. As crianças eram abandonadas por seus pais; expostas, em sua própria família, às mais diversas formas de violência física, emocional e sexual, sem que houvesse punição alguma. Os pais tinham total domínio sobre seus filhos, de modo que a violação de direitos destes era tratada como algo pertencente à esfera privada.

\footnotetext{
${ }^{1}$ Fundação Estadual do Bem-estar do Menor. Os "menores" em situação irregular e abandonados eram tratados com rigidez e disciplina interna nestas instituições, que eram rodeadas por muros altíssimos e cujas portas eram fechadas para a sociedade, o que tornava ineficaz a premissa da proteção, educação e assistência que deveriam ser seus objetivos centrais (COSTA, 1993b).
} 
A demanda pelo ingresso da proteção dos direitos da infância e juventude na agenda de políticas públicas no Brasil foi um processo que começou mais de uma década antes da promulgação da CF/88. Assim, inspiradas pelo projeto da Convenção dos Direitos da Criança da ONU, em 1986, organizações não governamentais de defesa dos direitos da infância e juventude começaram a fomentar um movimento para que as medidas de proteção ingressassem na CF/88. González (2015) afirma que:

[...] no período da Assembleia Nacional Constituinte surgiram duas articulações políticas. A Comissão Criança e Constituinte foi criada em 1986 pelo Presidente José Sarney, por sugestão do UNICEF, reunindo diversos Ministérios e entidades não governamentais como OAB, CNBB, Sociedade Brasileira de Pediatria, Organização Mundial de Educação Pré-Escolar (OMEP) e Federação Nacional dos Jornalistas (FENAJ). Ela realizou seu primeiro seminário em outubro de 1986; organizou uma emenda popular (Emenda no 64) apresentada à Assembleia Nacional Constituinte (POERNER, 1987), bem como a Campanha Criança Prioridade Nacional, organizada pelo Movimento Nacional de Meninos e Meninas de Rua e Pastoral do Menor, entre outros, que propôs a emenda popular 096, coletando assinaturas. Estas emendas foram posteriormente fundidas, levando à proposta de redação do Art. 227 da Constituição Federal (GONZÁLEZ, 2015, p. 29).

Com a promulgação da Constituição Cidadã, especificamente por meio do artigo 227, foram definidos os deveres do Estado, da família e da sociedade na proteção dos direitos que conferem cidadania às crianças e adolescentes no Brasil (BRASIL, 1988). Ainda, a Constituição Federal instituiu, para este público, a prioridade na criação e implementação de políticas públicas.

O Projeto de Lei que regulamentou o artigo 227 da CF/88 e elaborou o ECA ingressou no Congresso Nacional em junho de 1989, sendo aprovado em junho de 1990 e sancionado em 13 de outubro de 1990. Com a promulgação do ECA, revogou-se expressamente o Código de Menores (Lei no 6.697/1979), que se baseava no paradigma do menor em situação irregular, ou seja, buscava "[...] atender os desvalidos, infratores e abandonados, buscando meios de corrigir as supostas causas dos 'desajustamentos' dos menores" (MOURA, 2016, p. 3).

O ECA atribuiu a toda sociedade e ao Estado a obrigação do tratamento prioritário de proteção dos direitos e efetivação da cidadania das crianças e dos adolescentes brasileiros. Esta legislação gerou uma reorganização das instituições, como a criação da Fundação Centro Brasileiro para a Infância e a Adolescência (CBIA), em substituição à Fundação Nacional do Bem-Estar do Menor (FUNABEM), e com o objetivo de construir políticas públicas para a área, incentivando a criação de Conselhos de Direitos da Criança e Adolescente, Conselhos Tutelares e redes de proteção social estaduais e municipais.

Diante da criação desta base legislativa, ancorada na doutrina de proteção integral a crianças e adolescentes, atribuiu-se uma nova tarefa à sociedade brasileira na defesa dos direitos da infância, a de mudar as práticas e a cultura, tanto das instituições de acolhimento como da sociedade em geral, quanto à tolerância ao uso da violência e ao desrespeito dos direitos das crianças e adolescentes, principalmente os mais vulneráveis socioeconomicamente (GONZÁLEZ, 2015).

\section{O Sistema de Proteção à Criança e ao Adolescente}

A adoção pelo Estado brasileiro da doutrina da proteção integral a crianças e adolescentes, com a criação do ECA, mudou radicalmente o panorama de políticas públicas destinadas a esta parcela da população brasileira.

Segundo a doutrina da proteção integral, as crianças e os adolescentes no Brasil foram considerados pessoas em desenvolvimento e sujeitos de uma gama de direitos que deveriam ser garantidos por parte do Estado e de toda a sociedade. Assim, o desenvolvimento desses sujeitos ocorreria com plena segurança, mediante acesso a todos os recursos para a consolidação da sua cidadania, ao contrário da doutrina anteriormente adotada, que previa a intervenção do Estado somente quando crianças e adolescentes eram vítimas de abandono ou realizavam algum ato infracional.

Esta legislação determinou uma nova responsabilidade aos estados e aos municípios na criação e implementação de políticas públicas que garantissem a efetivação da cidadania e a proteção contra a violação dos direitos da infância e juventude. Inúmeras instituições foram constituídas, como os Conselhos de Direitos da Criança, os Conselhos Tutelares, os Fundos de Direitos da Criança e a Ação Civil Pública.

O ECA, por exemplo, reforçou a responsabilidade do Judiciário na defesa dos direitos da infância e juventude com a atuação dos Ministérios Públicos estaduais, que passaram a ter promotorias especializadas, assim como os Tribunais de Justiça Estaduais, com o recurso a varas judiciais especializadas na defesa e efetivação de direitos. 
De igual forma, o ECA sinalizou a descentralização das políticas públicas, por meio da qual os estados e os municípios brasileiros deveriam implementar uma rede de proteção social, articulando diversas instituições estatais e atores para a defesa dos direitos da infância e juventude mediante criação e implementação de tais políticas destinadas a total proteção. Determinou, ainda, que este público deveria ser sempre priorizado quando da criação e implementação de políticas públicas, para que possuam proteção contra violações e tenham garantidas cidadania plena e oportunidade de desenvolvimento pessoal e profissional.

Assim, deu-se início ao processo de criação e implementação das políticas públicas e de instituições para a defesa e a proteção da cidadania e dos direitos de crianças e adolescentes pelos municípios e estados. Houve estímulos da CBIA, para que fossem criados Conselhos Tutelares e Conselhos da Criança e Adolescente nos estados e municípios. Esta fundação tinha por "[...] objetivo formular, normalizar e coordenar, em todo território nacional, a Política de Defesa de Direitos da Criança e do Adolescente, bem assim, prestar assistência técnica a órgãos e entidades que executam esta política" (BRASIL, 1994, Art. 3ㅇ). Foi extinta, no entanto, no início do governo Fernando Henrique Cardoso, o que levou, assim, ao fim do estímulo financeiro a estados e municípios para a criação e o funcionamento destas instituições (GONZÁLEZ, 2000).

É preciso ressaltar que alguns dos estados e municípios conseguiram criar os sugeridos Conselhos, porém não os colocaram em funcionamento. Em outros casos, os Conselhos entraram em funcionamento, mas não possuíam reais atribuições e capacidades para efetivar a cidadania e proteger os direitos da infância e juventude.

\section{Os Conselhos}

A CF/88 fundamentou a atuação das ações e políticas governamentais na área da assistência social. No artigo 204, é apresentada a organização dessa área:

I- [...] [cabem] a coordenação e as normas gerais à esfera federal e a coordenação e a execução dos respectivos programas às esferas estadual e municipal, bem como a entidades beneficentes e de assistência social;

II - participação da população, por meio de organizações representativas, na formulação das políticas e no controle das ações em todos os níveis (BRASIL, 1988, Art. 204).

Como pode ser observado, objetivou-se realizar a descentralização das ações e simultaneamente estimular a participação popular; assim, os conselhos populares teriam o potencial de aplicação da doutrina da proteção integral no âmbito dos direitos da infância e juventude (CARDOZO, 2011).

Sabe-se que os conselhos instituídos, tanto os Conselhos de Direitos da Criança e do Adolescente, quanto o Conselho Tutelar, vieram para agrupar o conceito de participação da população nas políticas sociais de proteção, unindo os conceitos de participação e proteção integral (CARDOZO, 2011). São, portanto, instrumentos para o desenvolvimento das políticas sociais e para a proteção integral à criança e ao adolescente em todos os níveis, em especial, no municipal.

Os Conselhos Tutelares são órgãos mediadores das políticas de assistência à criança e ao adolescente atuando de forma executiva na fiscalização e na cobrança do bom funcionamento da rede de proteção municipal:

[...] a combinação desses preceitos a outro que afirma que um dos objetivos da assistência social é o amparo às crianças e adolescentes carentes (BRASIL, 1988, art. 203), além da gravidade social do desamparo de crianças e adolescentes pobres no país, talvez explique a profunda articulação, que, na prática, existe na implementação de políticas de assistência social e de proteção e promoção de direitos de crianças e adolescentes. Os mecanismos criados para a construção dessa política inspiraram-se no desenho institucional da assistência social (1990a). O Estatuto prevê a "municipalização do atendimento" (1990a, art. 88), bem como a criação de Conselhos de Direitos da Criança e do Adolescente e de Fundos - nacional, estadual e municipal - por meio dos quais serão administrados os recursos destinados a essa política. As funções precípuas dos conselhos são supervisionar a aplicação dos recursos do fundo, em cada esfera da administração pública, e supervisionar as eleições e funcionamento do Conselho Tutelar. Diferentemente da área de assistência social, nesse caso existe o Conselho Tutelar que é o executor das políticas, agindo articuladamente com gestores públicos, Ministério Público e Poder Judiciário na proteção de direitos. Assim como na assistência social, os conselhos de direitos da criança e do adolescente têm caráter deliberativo e sua composição é paritária entre representantes do governo e da sociedade civil. Diferentemente, no entanto, neste caso, os representantes não governamentais são entidades que prestam serviços de proteção à infância e à juventude (CORTES, 2005, p. 156). 
O ECA iniciou o processo de efetivação dos conselhos de participação voltados à área de defesa dos direitos da infância e juventude. Desde sua implantação, deu-se o primeiro passo para a obediência ao preceito de participação popular nas políticas de assistência e atendimento aos direitos da criança e do adolescente, conforme estabelecido pela CF/88 (CARDOZO, 2011).

No mesmo sentido, surgiu o Conselho Nacional dos Direitos da Criança e Adolescente (CONANDA), instituído pela Lei no 8.242/91, que materializou um grande avanço no processo de modificação social, criando, assim, uma nova maneira de olhar a demanda de direitos da infância e juventude brasileira. Segundo Herbstrith-Willig (2004 apud CARDOZO, 2011, p. 29):

[...] a instituição envolveu um movimento muito forte para a instalação e a implementação dos Conselhos de Direitos da Criança e do Adolescente e dos Conselhos Tutelares, tanto em nível estadual como municipal, já que o Estatuto adota a doutrina da municipalização dos assuntos pertinentes a esse tema. A municipalização, no ECA, reflete a isenção da União e do Estado de parte do poder que mantinham até então nessa matéria. O município, pela sua autonomia, passa a praticar e executar a política de atendimento dos direitos da criança e do adolescente, de acordo com as necessidades de sua região, tendo como principais instrumentos o Conselho Municipal da Criança e do Adolescente e o Conselho Tutelar.

Dessa forma, os conselhos criados como resultado da lei que instituiu o ECA configuram as principais ferramentas de participação da população e de mudança de mentalidade, porque reafirmam a máxima constitucional de que é papel de toda sociedade zelar pela proteção de crianças e adolescentes. De acordo com o exposto, o ECA traz importantes ferramentas de implementação de políticas sociais e criação de órgãos, para que a prioridade em atendimento e o zelo, trazidos no texto da Carta Magna, sejam operacionalizados nos níveis estadual e municipal, visto que são os níveis de governo mais próximos do público a ser atendido.

O ECA "[...] garante que todas as crianças e adolescentes, independente de cor, raça ou classe social, sejam tratados como cidadãos que precisam de atenção, proteção e cuidados especiais para se desenvolverem e serem adultos saudáveis" (PARANÁ, 2010, p. 44). Inicialmente, explicita os direitos da infância e juventude quanto à vida, à educação, à saúde, à liberdade, à dignidade, à convivência familiar, ao esporte, à cultura e ao lazer, ao trabalho, e à prevenção à ameaça e violação de direitos (BRASIL, 1990, Art. 1ㅇ - 85ㅇ), bem como enumera os princípios que norteiam a aplicação destes direitos. Também deixa claro que crianças e adolescentes são prioridade no desenvolvimento de políticas públicas de saúde, assistência, educação e proteção.

Dos artigos 86 a 267, o ECA trata das normas a serem utilizadas para corrigir os desvios, e/ou para ter acesso ao Estado brasileiro, sem abuso ou omissão das garantias desses direitos (PARANÁ, 2010, p. 44). 0 artigo 86 descreve o modelo de atendimento e realização das políticas sociais para a infância e juventude, determinando as linhas de atuação e, de forma geral, o desenho das políticas públicas. $O$ artigo 88 também cita e fixa as diretrizes para a elaboração das políticas de atendimento à criança e ao adolescente (BRASIL, 1990).

Os dois conselhos citados pelo ECA possuem papéis definidos em relação às políticas sociais de atendimento. O CONANDA (s.d.) constitui-se de “[...] órgãos deliberativos responsáveis por assegurar, na União, nos estados e nos municípios, prioridade para a infância e a adolescência [...] os conselhos formulam e acompanham a execução das políticas públicas de atendimento à infância e à adolescência". Eles atuam no registro e na coordenação das políticas de assistência e proteção, além de fiscalizar o cumprimento da legislação que assegura os direitos humanos da criança e do adolescente:

[...] constituídos, de forma paritária, por representantes do governo e da sociedade civil, os conselhos estão vinculados administrativamente ao governo do estado ou do município, mas têm autonomia para pautar seus trabalhos e para acionar Conselhos Tutelares, as Delegacias de Proteção Especial e as instâncias do Poder Judiciário, como o Ministério Público, as Defensorias Públicas e os Juizados Especiais da Infância e Juventude, que compõem a rede de proteção aos direitos de crianças e adolescentes (PARANÁ, 2010, p. 23).

Conselho Tutelar consiste no "[...] órgão encarregado pela sociedade, através do voto, de zelar pelo cumprimento dos deveres e direitos da criança e adolescente" (PARANÁ, 2010, p. 7), atuando no atendimento assistencial direto da criança e do adolescente e na fiscalização das políticas sociais. O Conselho Tutelar opera como órgão executivo e, ao mesmo tempo, órgão intermediador entre todos os elos da rede de proteção, tais como postos de saúde (política de saúde), escolas (educação); no seu papel fiscalizador, atua juntamente com o Ministério Público e a Justiça Estadual. 


\section{O Conselho Tutelar e os Burocratas de Rua}

Tendo surgido com a edição do ECA, e conforme artigo 131 deste, o Conselho Tutelar é um órgão autônomo, não jurisdicional. O referido artigo dispõe ainda, de maneira geral, da finalidade do Conselho, qual seja, zelar pela proteção e efetivação dos direitos das crianças e adolescentes.

O Conselho Tutelar constitui órgão permanente, ou seja, "[...] uma vez criado por lei municipal não poderá mais ser desconstituído" (ROSÁRIO, 2002, p. 18). Para o funcionamento do órgão, haverá em cada município pelo menos cinco conselheiros tutelares a serem escolhidos pela comunidade deste para um mandato de 3 anos, sendo permitida a recondução. Para se candidatar a conselheiro tutelar, o candidato, necessariamente, deve ter reconhecida idoneidade moral, idade superior a vinte e um anos e residir no município ao qual se candidatou (BRASIL, 1990, Art. 133). Contudo, "[...] a lei municipal poderá estabelecer critérios mais restritivos como formação superior, aprovação prévia em exame de conhecimento ou participação em curso prévio de formação" (MARTINS e CUSTÓDIO, 2018, p. 3). É obrigatória a implementação de um Conselho Tutelar em cada município brasileiro, podendo a Lei Municipal que institui o órgão prever a criação de mais Conselhos, ou microrregiões, para melhor atendimento do público infanto-juvenil. A resolução no 75 do CONANDA recomenda que exista um Conselho Tutelar para cada grupo de 200.000 habitantes.

O ECA é a legislação geral que regula as medidas, e o procedimento de atuação com relação às medidas de atendimento deve ser regulado e determinado por legislação municipal editada. De maneira geral, as Leis Municipais dispõem procedimentos de realização e pedido de diligências, visitas a locais para fiscalização, bem como visita a locais e residências, a fim de assegurar a proteção de direitos. É importante destacar que o Conselho Tutelar possui característica peculiar, já que possui poder executivo, ausente em todos os outros tipos de conselhos no Brasil. Ou seja, mesmo sendo um conselho, possui uma característica muito distinta dos demais, qual seja, o poder de executar medidas que achar cabíveis dentro de sua legitimidade e de suas atribuições legais definidas pelo ECA e pela respectiva Lei Municipal.

Os direitos a serem protegidos pelo Conselho Tutelar em sua atuação encontram-se descritos no artigo 227 da CF/88 e novamente afirmados pelo artigo 4ㅇ do ECA, o qual dispõe ser "[...] dever da família, da comunidade, da sociedade em geral e do poder público assegurar, com absoluta prioridade, a efetivação dos direitos referentes à vida, à saúde, à alimentação, à educação, ao esporte, ao lazer, à profissionalização, à cultura, à dignidade, ao respeito, à liberdade e à convivência familiar e comunitária" (BRASIL, 1990, Art. 4ํ).

O Conselho Tutelar atua como mediador e fiscalizador dos direitos e das políticas de atendimento à criança e ao adolescente, constituindo um órgão que proporciona uma aproximação entre a sociedade e o Estado. Neste contexto, os conselheiros podem ser analisados com base na teoria da burocracia ao nível da rua, formulada por Lipsky (1980). Os "burocratas do nível de rua" são aqueles funcionários "[...] que interagem diretamente com os cidadãos no curso de seus trabalhos, e que têm critérios substanciais na execução do serviço que desempenha" (1980, p. xii). Nesta denominação, podem-se enquadrar, segundo Lotta (2014), policiais, professores, agentes de saúde, assistentes sociais, fiscais, entre outros, que trabalham diretamente com os beneficiários das políticas públicas. Suas ações, durante a implementação, são extremamente relevantes, uma vez que "[...] desempenham atividades-fim, [e] as rotinas que eles estabelecem, os expedientes que eles criam para contornar a incerteza e as pressões é que vêm a ser de fato as políticas públicas" (LIPSKY, 1980, p. xii).

Nas políticas públicas de proteção à infância e juventude, os conselheiros tutelares são os burocratas ao nível de rua. Eles podem ser considerados a "ponta de lança" destas ações, em virtude de sua relação direta com o usuário e de uma influência considerável na qualidade da política. Esta influência manifesta-se, dentre outros elementos, em crenças, valores e vivências dos implementadores, visto que "[...] as ideias e os valores dos atores executores, de forma interdependente, influenciam a conformação da trajetória da política pública e seus resultados" (LIMA e D’ASCENZI, 2013, p. 16).

Ao Conselho Tutelar compete: a fiscalização de entidades de atendimento responsáveis pela execução dos programas de proteção e socioeducativos, tanto governamentais como não governamentais, instaurando procedimento judicial de apuração de irregularidades nestas entidades, quando necessário; instauração de procedimento de apuração de infração administrativa às normas de proteção à criança e ao adolescente; atendimento às crianças e aos adolescentes cujos direitos encontrem-se ameaçados ou lesados; atendimento à criança autora de ato infracional; atendimento aos pais ou responsável; promover a execução de suas decisões; e a execução de medida de proteção ao adolescente infrator (MINISTÉRIO PÚBICO DO PARANÁ, s. d.).

O Conselho é competente para trabalhar em conjunto com os órgãos jurisdicionados, tanto na prevenção de violações de direitos, realizando palestras e orientando à população, quanto no encaminhamento de providências judiciais que fogem à sua 
competência. Dentre suas atribuições estão: requisitar, notificar, encaminhar e aplicar medidas necessárias aos atendimentos de crianças e adolescentes juntamente com suas famílias. Desse modo, o Conselho Tutelar atua como um articulador de demandas, das mais diversas, da população infantil e juvenil, que chegam até ele por meio de denúncias e da procura da família ou responsáveis. Diante disso, ele atua executivamente ou realiza a mediação entre crianças e adolescentes e suas famílias e os órgãos estatais que executam as políticas públicas de atendimento.

De igual forma, dá-se a relação entre o Conselho Tutelar e a escola. Esta encaminha denúncias sobre violações (quando externas a ela ou em situação de evasão escolar), diante das quais o Conselho atua como mediador entre a família ou responsáveis, e a escola procura solucionar o problema e garantir o direito à educação à criança ou ao adolescente. Em outras circunstâncias, 0 Conselho possui legitimidade para encaminhar casos ao Poder Judiciário, tanto para o Ministério Público como para a Justiça Estadual. Exemplo dessa situação é a necessidade de ingresso de ações para requerer acesso ao sistema de saúde e denunciar crimes contra a vida, bem como casos de crimes de maus tratos e violações mais graves de diretos.

Uma particularidade dos conselheiros tutelares é que, mesmo sendo burocratas ao nível de rua, não sofrem pressão do Estado quanto à efetivação das política que executam. O que ocorre em virtude de o Conselho Tutelar ser um orgão autônomo, não subordinado a nenhum outro órgão, vinculado apenas ao Poder Executivo (ROSÁRIO, 2002). Além disso, em razão de serem eleitos, os conselheiros sofrem a pressão clássica da democracia eleitoral. Segundo Cantalice, Não obstante(...)

[...] figurar como uma eleição direta, a prerrogativa da autonomia e da legitimidade política, tanto durante o processo quanto na atuação dos seus respectivos eleitos não têm se consolidado. Tendo em vista que, de forma ampla e contundente, é observada a ação tutelada de seus membros, por ingerência direta e indireta de partidos políticos, parlamentares, igrejas, Estado e até da iniciativa privada, que ditam regras e ações nos Conselhos, cujos fins se coadunam com a reprodução e com o atendimento dos interesses que representam, em detrimento das ações voltadas a exigibilidade dos direitos de crianças e adolescentes previstos nas legislações pertinentes a esta área (CANTALICE, 2011, p. 49).

Por conseguinte, dada a escolha dos conselheiros via eleições pela comunidade, ela se assemelha, muitas vezes, a "[...] uma disputa político-partidária aos moldes das eleições gerais do sistema político representativo brasileiro" (PAIVA, 2011, p. 126). Contexto em que a condição financeira para o financiamento da campanha pode influenciar no resultado do processo, e não somente a trajetória de luta e interação do candidato com a sociedade. Aliado a isso, o candidato escolhido pode não ser o mais atuante e comprometido e, sim, o mais articulado e carismático. Ademais, o cargo de conselheiro tutelar, por muitas vezes, serve como trampolim político-eleitoral, uma vez que o Conselho torna-se uma grande vitrine para futuro cargo político na esfera do legislativo e executivo municipal.

Também devem ser consideradas as condições precárias dos locais onde grande parte dos conselheiros executa suas atividades. Ou seja, "[...] não possuem lugar adequado para o atendimento das demandas, por vezes dividem o mesmo espaço físico com outros órgãos; não possuem telefone, acesso à internet e transporte; e, também, não contam com equipamentos sociais da rede de proteção à criança e ao adolescente - como casa de acolhida, de passagem, abrigo, dentre outros" (CANTALICE, 2011, p. 48). Essas situações podem interferir diretamente na implementação das políticas públicas e no trato das questões de proteção aos direitos da criança e do adolescente. Isso significa dizer que somente uma legislação avançada na proteção dos direitos da infância não basta para que sejam implementadas políticas públicas que assegurem a efetividade desta proteção. Os executores das políticas cumprem um papel fundamental e, por isso, precisam ser valorizados, capacitados e equipados para qualificar a execução do trabalho.

\section{O Conselho Tutelar de Pelotas/RS}

O município de Pelotas está localizado na região sul do Estado do Rio Grande do Sul, estendendo-se por 1.610,10 km², e possui, de acordo com o IBGE (2010), 328.275 habitantes. Seu Conselho Tutelar foi instituído pela Lei Municipal no 4.838 de 27 de julho de 2002, a qual criou 15 cargos de conselheiro tutelar, três microrregiões, alocando cinco conselheiros em cada uma delas. A Lei ainda dispõe sobre a criação de corregedoria e coordenadoria do Conselho Tutelar com atribuições de fiscalização e levantamento de dados para o Conselho Estadual da Criança e do Adolescente. Em 2010, com a edição da Lei Municipal no 5.775, de 31/09/2010, aumentou-se para 20 os cargos de conselheiro tutelar. Por fim, com relação à base legal referente ao Conselho Tutelar em Pelotas/RS, a Lei no 6.341 de 03 de abril de 2016 criou mais duas microrregiões, com seis cargos cada, totalizando 30 conselheiros tutelares no município. 
Para concorrer ao cargo de conselheiro tutelar, o candidato deve ter: reconhecida idoneidade moral, idade igual ou superior a 21 anos na data da posse, residência em Pelotas, "[...] Ensino Fundamental completo; avaliação psicológica atestando a capacidade para o trabalho, emitido por psicólogo; estar ciente das características do regime de trabalho com dedicação exclusiva" (PELOTAS, 2019).

O processo de seleção para o Conselho Tutelar em Pelotas/RS é composto de duas fases: a primeira, de uma prova objetiva, de cunho eliminatório; a segunda, de pleito eleitoral, da qual participam os aprovados na primeira. $O$ voto é facultativo e secreto, todos os eleitores do município podem participar do processo (PELOTAS, 2019), cuja fiscalização fica a cargo do Ministério Público e da Justiça Eleitoral. A prova objetiva de conhecimentos específicos constitui-se em um diferencial na seleção dos candidatos no município de Pelotas em virtude de seu caráter eliminatório, uma vez que que busca selecionar, entre os candidatos, aqueles que possuem conhecimento técnico para a investidura no cargo.

Para aferir as atribuições legais do Conselho Tutelar em relação ao cotidiano vivido pelos conselheiros no município de Pelotas/RS, foram realizadas entrevistas em profundidade com 12 (doze) conselheiros. Dos conselheiros do período 2016-2019, 50\% estão na faixa de 25 a 45 anos. Dez entrevistados possuem ensino superior incompleto ou em andamento, em cursos de licenciatura, pedagogia, história, geografia e direito. Há, também, conselheiros com ensino fundamental e médio.

Em resposta ao questionamento sobre a motivação para o Conselho Tutelar, a maioria respondeu que, antes de realizar o processo seletivo para o cargo, já havia tido algum contato com trabalho comunitário: alguns realizaram trabalho voluntário com crianças e adolescentes, outros, como agentes de saúde, ou seja, algum tipo de trabalho social, não necessariamente remunerado.

Quanto aos objetivos do trabalho, os conselheiros tutelares são unânimes em afirmar que se trata da garantia dos direitos da criança e do adolescente e da atuação no sentido de evitar ou solucionar violações a estes direitos. Dentro desses objetivos, tem-se, ainda: a garantia do direito à saúde, na medida em que realizam as requisições e os encaminhamentos para as políticas públicas de saúde; garantia dos direitos humanos, uma vez que o Conselho Tutelar possui a legitimidade para intervir em casos de denúncia de crimes contra a vida e contra a integridade física de crianças e adolescentes, bem como para proteção às mais diversas violações. Este consenso comunica-se com o objetivo principal do órgão que representa a garantia e o zelo pelos direitos da infância e juventude, conforme estabelecido em lei.

Já em relação aos instrumentos disponíveis para atingir os objetivos do órgão, os conselheiros são bem menos otimistas. Os entrevistados afirmam que o conselho possui grande dificuldade em alcançar seus objetivos, em virtude das falhas na rede de atendimento à criança e ao adolescente, ou seja, as outras instituições do sistema não conseguem atender adequadamente quando demandadas.

Pensando na dificuldade do alcance dos objetivos dos Conselhos Tutelares, retorna-se, aqui, aos burocratas ao nível de rua, que, apesar de terem sua importância diversas vezes secundarizada, podem causar grandes impactos; muitas vezes, negativos. Por exemplo, a ausência de especialidades limita fortemente o trabalho do Conselho, o que leva à descaracterização do formato das políticas. Outro aspecto limitante constatado diz respeito à dificuldade de informatizar a rede de proteção, que agilizaria a requisição de documentos e serviços.

No que tange à motivação para a ação do Conselho, os entrevistados foram unânimes em informar que atuam mediante provocação, ou seja, basicamente reagem às denúncias. Geralmente, não há proatividade e/ou um trabalho preventivo por parte dos conselheiros; quando desenvolvem iniciativas desse tipo, são pessoais e individuais o que demonstra que a discricionariedade desse servidor público (burocrata ao nível de rua) é muito pouco limitada.

O 'modus operandi' do Conselho Tutelar, normalmente, dá-se da seguinte forma: a denúncia é recebida de maneira anônima, ou por escolas, hospitais e demais órgãos que possuem o dever legal de informar algum indício de violação de direitos de crianças ou adolescentes. Em seguida, de acordo com o caso, os conselheiros tomam as providências necessárias. Em denúncias mais graves, como supostos crimes contra a integridade física, o protocolo é ir ao local e averiguar a procedência para, em caso positivo, informar ao Ministério Público. Em face ao poder executório, o Conselho Tutelar, em casos extremos, retira a criança do ambiente hostil ou até mesmo determina o afastamento imediato do suposto abusador.

A pesquisa revelou claramente o papel do Conselho Tutelar como um articulador entre crianças, adolescente e família e as políticas públicas oferecidas pelo Estado. Todavia o Conselho age como um "pronto-socorro", para onde as famílias se dirigem em busca de solução dos mais diversos problemas, até mesmo alguns que não são da competência do órgão. 
Com relação aos tipos de atendimento mais frequentes, a pesquisa revelou fortes distinções geográficas nas microrregiões responsáveis pelo atendimento ao centro da cidade, onde os casos mais frequentes são relacionados a conflitos familiares, abuso de drogas, abuso físico e sexual, e evasão escolar. Nas regiões mais longínquas do centro, como na Colônia de Pescadores $\mathrm{Z3}$, os casos mais frequentes estão relacionados a trabalho infantil e casamentos de adolescentes menores de 14 anos.

Sobre a solução dos casos, os conselheiros reafirmam o dever de articular os serviços com a rede de atendimento, cujas políticas públicas de saúde, educação e atendimento na cidade de Pelotas/RS muitas vezes são falhas. Os problemas estruturais também contribuem para o insucesso na solução dos casos, já que faltam insumos básicos como salas de atendimento equipadas, materiais de escritório e, principalmente, um sistema de informação que conecte a rede de proteção social. Muitos conselheiros utilizam material de trabalho adquirido com recursos pessoais, o que é completamente inaceitável para o serviço público.

A ligação entre a sociedade e o Estado para promover a proteção do direito da criança e do adolescente, como foi demonstrado no decorrer da pesquisa, é feita pelo Conselho Tutelar. No entanto, por muitas vezes, o serviço necessário à resolução da demanda não é disponibilizado pelo município ou, então, é prestado de maneira deficitária, dificultando a resolução dos casos e a garantia dos direitos.

\section{CONSIDERAÇÕES FINAIS}

O Conselho Tutelar tem uma constituição bastante particular, pois é legalmente autônomo, não subordinado a outro órgão, vinculado apenas ao Poder Executivo. As principais atribuições do Conselho Tutelar são aquelas legalmente estabelecidas pelo ECA, cujo princípio fundamental é garantir e zelar pelos direitos da criança e do adolescente agindo como articulador entre a sociedade e o Estado. Funciona como um elo entre os órgãos que compõem a rede de proteção de crianças e adolescentes. O Conselho Tutelar é a "ponta de lança" das políticas públicas.

No município de Pelotas, o Conselho Tutelar age de forma análoga a um grande "pronto-socorro", realiza a triagem para que crianças e adolescentes possam ter acesso a políticas públicas e para que possam ser protegidos quando vítimas de algum abuso ou crime.

Os conselheiros podem influenciar consideravelmente a qualidade das políticas implementadas. Essa influência pode se manifestar em razão de crenças, valores e vivências dos implementadores ou, ainda, em razão de o conselheiro atuar em prol de interesses individuais, privados, partidário ou de determinados grupos, em detrimento das demandas coletivas. Aliado a isso, o não efetivo funcionamento da rede de atendimento obsta, muitas vezes, a proteção dos direitos, visto que muitos serviços não são disponibilizados pelo município ou o são de maneira inadequada ou insuficiente.

O Conselho Tutelar atua quase que exclusivamente por provocação; ou seja, quando os casos chegam por meio de denúncia. A partir daí os conselheiros iniciam seu trabalho fazendo a triagem do caso, requisitando serviços, averiguando a denúncia in loco ou acionando o Ministério Público. Os conselheiros tutelares articulam e conectam a sociedade às políticas públicas. Enfim, o órgão zela pelos direitos, ajuda a efetivá-los e ainda fiscaliza outros órgãos.

A peculiaridade do processo de seleção para o Conselho Tutelar, cuja segunda fase é formada por uma eleição, configura-se como entrave para o seu bom funcionamento, na medida em que, muitas vezes, os Conselhos Tutelares tornam-se "cabides de emprego" para alguns políticos, o que contamina o trabalho, afinal, uma das suas funções legais é fiscalizar órgãos e políticas públicas municipais. Ademais, o cargo de conselheiro tutelar, por muitas vezes, serve como trampolim político-eleitoral em razão da sua visibilidade pública.

Os resultados encontrados são bastante promissores pois indicam que a eleição dos conselheiros tutelares contribui para a efetividade e qualidade da política pública, contudo o formato de seleção parece limitado pelas mesmas razões do sistema representativo proporcional brasileiro, ou seja, os eleitos não são os mais capazes, comprometidos ou representativos das entidades de proteção, mas sim aqueles que articulam melhor o capital eleitoral.

Esta pesquisa permitiu confirmar parcialmente a hipótese inicial de que o Conselho Tutelar é protagonista na proteção dos direitos da criança e do adolescente quando estão ausentes ou omissos pais e familiares. Não obstante, não consegue solucionar de forma efetiva a totalidade dos casos em razão do isolamento e fragmentação do sistema de proteção e, também, da postura reativa dos conselheiros e da falta de infraestrutura no trabalho. 


\section{REFERÊNCIAS}

BRASIL. Constituição da República Federativa do Brasil. Brasília, DF: Senado Federal: 1988.

BRASIL. Decreto no 1.302, de 4 de novembro de 1994. Aprova o Estatuto e o Quadro Demonstrativo de Cargos em Comissão e Funções de Confiança da Fundação Centro Brasileiro para a Infância e Adolescência - CBIA. 1994. Disponível em: <http://www.planalto.gov.br/ccivil_03/ decreto/1990-1994/D1302.htm>. Acesso em: 03 out. 2019.

BRASIL. Lei no 8.069, de 13 de julho de 1990. Dispõe sobre o Estatuto da Criança e do Adolescente e dá outras providências. 1990. Disponível em: <http://www.planalto.gov.br/ccivil_03/leis/L8069Compilado. htm>. Acesso em: 26 out. 2020.

BRASIL. Lei no 8.242, de 12 de outubro de 1991. Cria o Conselho Nacional dos Direitos da Criança e do Adolescente (Conanda) e dá outras providências. 1991. Disponível em: <http:// http://www. planalto.gov.br/ccivil_03/leis/l8242.htm>. Acesso em: 26 out. 2020.

CANTALICE, L.B. A produção do conhecimento em torno dos Conselhos Tutelares: uma análise de teses e dissertações. In: SOUZA FILHO, R.; SANTOS, B. R.; DURIGUETTO, M. L. (Orgs.). Conselhos Tutelares: desafios teóricos e práticos da garantia de direitos da criança e do adolescente. Juiz de Fora, Ed: UFJF, 2011.

CARDOZO, A. Conselho Tutelar como instrumento de participação da população e de efetivação de política social de atendimento da criança e adolescente. 2011. Trabalho de Conclusão de Curso (Bacharel em Ciências Jurídicas e Sociais) - Pontifícia Universidade Católica do Rio Grande do Sul, Faculdade de Ciências Jurídicas e Sociais, Porto Alegre, 2011.

CORTES, S. M. V. Arcabouço histórico-institucional e a conformação de conselhos municipais de políticas públicas. Educar em Revista, n. 25, p. 143-174, jun. 2005.

COSTA, A. C. G. É possível mudar: a criança, o adolescente e a família na política social do município. São Paulo: Editora Malheiros, $1993 a$.

COSTA, A. C. G. De menor a cidadão: notas para uma história do novo direito da infância e juventude no Brasil. Editora do Senado, 1993b.

GONZÁLEZ, R. S. Criança também é gente: a trajetória brasileira na luta pelo respeito aos direitos humanos da infância e juventude. In: VIOLA, S. et al. (Orgs.). Direitos humanos - pobreza e exclusão. São Leopoldo: Adunisinos, 2000. p. 143-158.

GONZÁLEZ, R. S. Políticas públicas para a infância no Brasil: análise do processo de implementação de um novo modelo. São Paulo: Editora Lume, 2015.

LIMA, L. L.; D’ASCENZI, L. Implementação de Políticas Públicas: perspectivas analíticas. In: ENCONTRO NACIONAL DE PESQUISADORES EM GESTÃo SOCIAL, 6., 2013, São Paulo. Anais... São Paulo: ENAPEGS, 2013. Disponível em: <http://anaisenapegs.com.br/2012/ dmdocuments/19.pdf>. Acesso em: 26 out. 2020.

LIPSKY, M. Street-Level Bureaucracy: dilemmas of the individual in public service. New York: Russell Sage Foundation, 1980.

LOTTA, G. S. Agentes de implementação: uma forma de análise de políticas públicas. Cadernos Gestão Pública e Cidadania, v. 19, n. 65, jul./dez. 2014. Disponível em: <http://bibliotecadigital.fgv.br/ojs/ index.php/cgpc/article/view/10870/40890>. Acesso em: 26 out. 2020.
MARTINS, M. D.; CUSTÓDIO, A. V. As atribuições dos conselhos tutelares na proteção aos direitos fundamentais da criança e adolescente. In: SEMINÁRIO INTERNACIONAL DE DIREITOS HUMANOS E SOCIEDADE, 1., 2018, Criciúma. Anais... Criciúma: Ed. UNESC, 2018. Disponível em: <http://periodicos.unesc.net/AnaisDirH/article/ download/4668/4275>. Acesso em: 04 out. 2019.

MINISTÉRIO PÚBLICO DO PARANÁ. Atribuições do Conselho Tutelar. 2019. Disponível em: <http://www.crianca.mppr.mp.br/pagina-161. html>. Acesso em: 01 out. 2019.

MOURA, M. B. Código de Menores à Criação do ECA: Estatuto da Criança e do Adolescente. Santa Rosa: Fundação Educacional Machado de Assis, 2016. Disponível em: <http://www.fema.com.br/ sitenovo/wp-content/uploads/2016/09/3-C\%C3\%B3digo-de-Menores\%С3\%A0-Cria\%C3\%A7\%C3\%A3o-do-Eca-\%E2\%80\%93-Estatuto-daCrian\%C3\%A7a-e-do-Adolescente.pdf>. Acesso em: 03 out. 2019.

PAIVA, A. B. Políticas de proteção à infância: o Conselho Tutelar de Ceilândia como foco de análise. In: SANTOS FILHO, R.; SANTOS, B. R.; DURIGUETTO, M. L. (Orgs.). Conselhos Tutelares: desafios teóricos e práticos da garantia de direitos da criança e do adolescente. Juiz de Fora: Ed: UFJF, 2011.

PARANÁ (Estado). O Professor PDE e os desafios da escola pública paranaense: produção didático-pedagógica. Vol. 2. 2010. Disponível em: <http://www.diaadiaeducacao.pr.gov.br/portals/cadernospde/ pdebusca/producoes_pde/2010/2010_uel_gestao_pdp_elcy_mori. pdf>. Acesso em: 02 out. 2019.

PELOTAS (Município). Lei Municipal n. 4.838, de 27 de junho de 2002. Cria funções populares providas mediante cargos em comissão, mecanismos de controle, funcionamento e organização interna dos Conselhos Tutelares e dá outras providências. 2002. Disponível em: <https://www.lexml.gov.br/urn/urn:lex:br;rio. grande.sul;pelotas:municipal:lei:2002-06-27;4838>. Acesso em: 26 nov. 2020.

PELOTAS (Município). Lei Municipal n. 5.575, de 31 de dezembro de 2010. Dispõe sobre os mecanismos de controle, funcionamento e organização interna dos Conselhos Tutelares e dá outras providências. 2010. Disponível em: <https://leismunicipais.com.br/a/rs/p/pelotas/ lei-ordinaria/2010/577/5775/lei-ordinaria-n-5775-2010-dispoesobre- os-mecanismos-de-controle-funcionamento-e-organizacaointerna-dos-conselhos-tutelares-e-da-outras-providencias>. Acesso em: 26 nov. 2020.

PELOTAS (Município). Lei Municipal n. 6.341, de 03 de abril de 2016. Dispõe sobre a criação de microrregiões para atuação de conselheiros tutelares no município e dá outras e dá outras providências. 2016. Disponível em: <https://sapl.pelotas.rs.leg.br/norma/2300>. Acesso em: 26 nov. 2020.

PELOTAS (Município). Prorrogadas as inscrições à eleição de conselheiros tutelares. Pelotas. 2019. Disponível em: <http://www. pelotas.com.br/noticia/prorrogadas-as-inscricoes-a-eleicao-deconselheiros-tutelares>. Acesso em: 03 out. 2019.

ROSÁRIO, M. O Conselho Tutelar como órgão de defesa de direitos num cenário de exclusão social. In: NAHRA, C. M. L.; BRAGAGLIA, M. (Orgs.). Conselho tutelar: gênese, dinâmica e tendências. Canoas: ULBRA, 2002. 
Hemerson Luiz Pase

ORCID: https://orcid.org/0000-0002-3322-3003

Doutor em Ciência Política pela Universidade Federal do Rio Grande do Sul (UFRGS); Professor associado na Universidade Federal do Rio Grande (FURG), Rio Grande - RS, Brasil. E-mail: hemerson.pase@gmail.com

\section{Gabriele Padilha Cunha}

ORCID: https://orcid.org/0000-0002-6798-7394

Mestre em Ciência Política pela Universidade Federal de Pelotas (UFPel), Pelotas - RS, Brasil. E-mail: gpcunha27@gmail.com

Márcia Leite Borges

ORCID: https://orcid.org/0000-0002-8609-6781

Doutora em Ciência Política pela Universidade Federal Fluminense (UFF); Pós-Doutoranda no Programa de Pós-Graduação em Direito e Justiça Social da Universidade Federal do Rio Grande (FURG), Rio Grande - RS, Brasil. E-mail: 1212.marcia@gmail.com

Ana Paula Dupuy Patella ORCID: https://orcid.org/0000-0002-9498-560X

Mestre em Direito e Justiça Social pela Universidade Federal do Rio Grande (FURG); Doutoranda em Ciência Política na Universidade Federal do Rio Grande do Sul (UFRGS), Porto Alegre - RS, Brasil. E-mail: anapaulapatella@gmail.com 